\title{
Endocrine remission of Cushing's disease after Endoscopic Transsphenoidal Surgery: a single centre experience
}

Devon Kennard, Benjamin Whitelaw, Dorota Dworakowska, Nick Thomas, Sinan Barazi, Peter Bullock, Andrew King, Tim Hampton, Charles Buchanan, Jackie Gilbert, Alan McGregor, Simon Aylwin

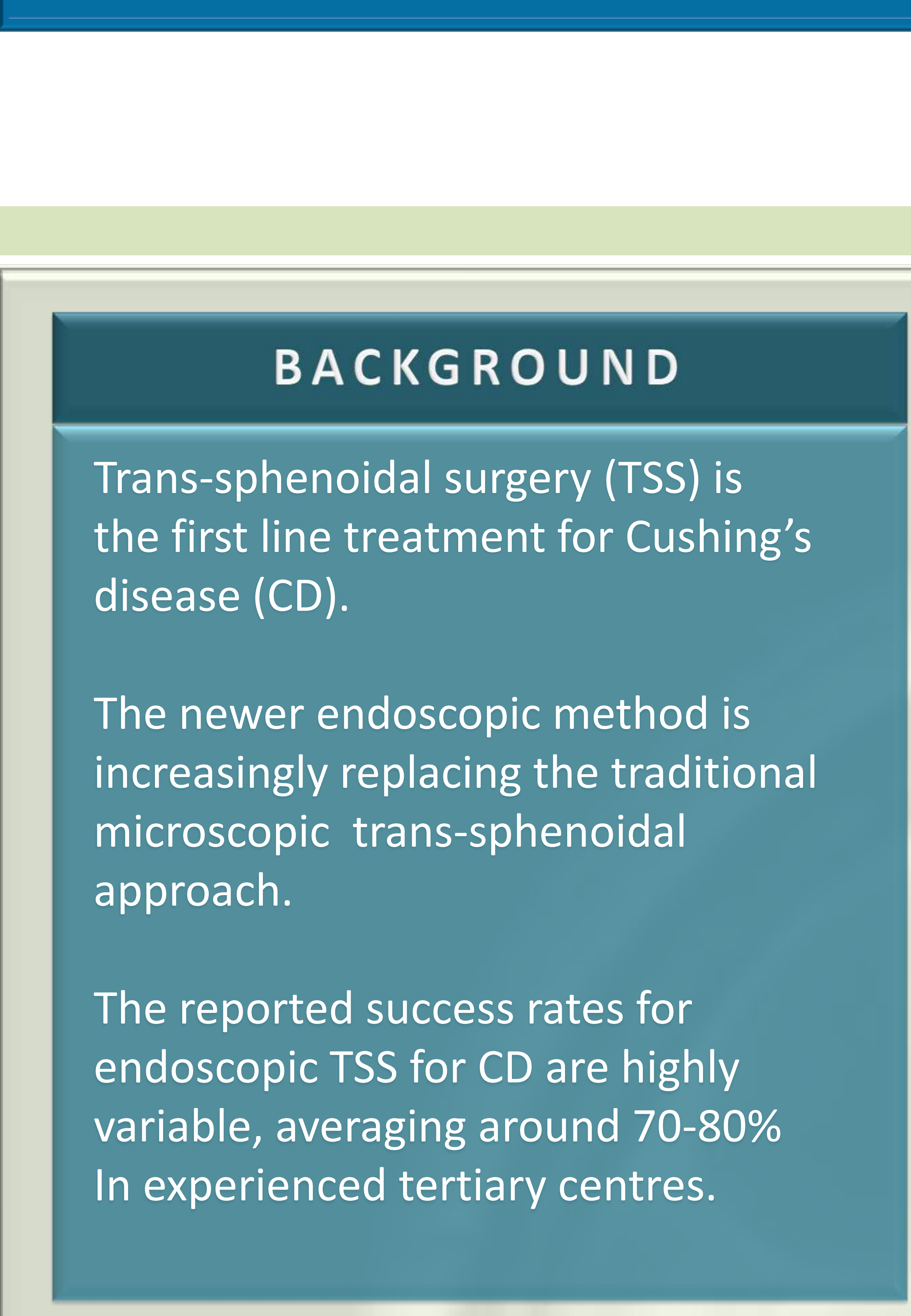

\section{OUR STUDY}

Our study was a retrospective audit of the endocrine remission rates for patients who had endoscopic TSS for suspected or proven $C D$.

Data was collected using the electronic patient database from Jan 2007, when the department commenced endoscopic surgery, until Nov 2012.

We also conducted a systematic review of the international literature in order to compare our remission rates with other centres.

\section{METHODS}

For the purpose of this analysis:

1. Patients who had surgery followed by a re-exploration during the same admission were treated as having a single surgical intervention.

2. Patients who had undergone previous pituitary surgery were excluded.

3. Post-operative remission was defined as serum cortisol $<50 \mathrm{nmol} / \mathrm{l}$ within 3 months of the surgical intervention.

\section{RESULTS}
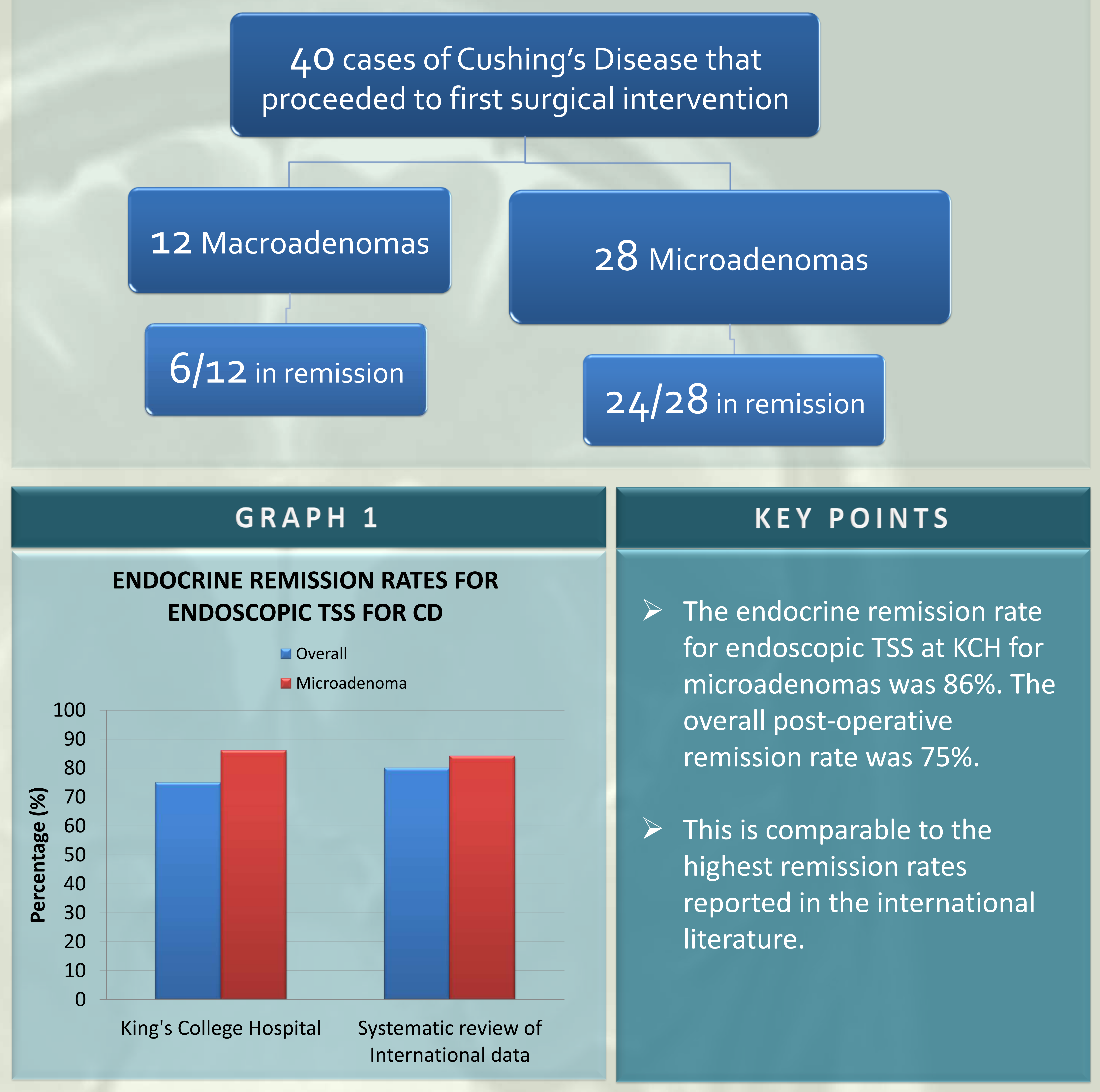

SYSTEMATIC REVIEW OF INTERNATIONAL

COMPARATIVE DATA FOR ENDOSCOPIC TSS FOR CD

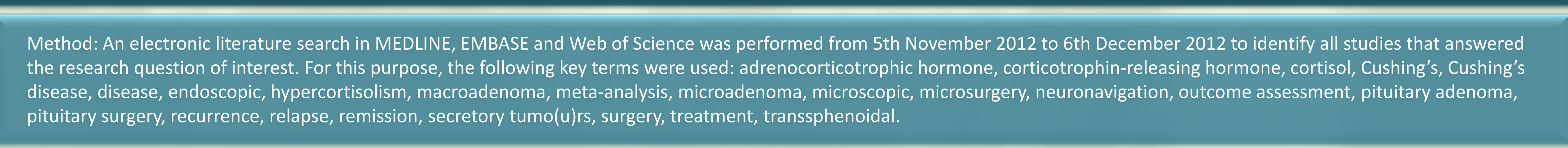
disease, disease, endoscopic, hypercortisolism, macroadenoma, meta-analysis, microadenoma, microscopic,
pituitary surgery, recurrence, relapse, remission, secretory tumo(u)rs, surgery, treatment, transsphenoidal.
Study, Year, Journal

Starke et al., 2012, Neurosurgery

Leach et al., 2010, Neurosurgery

Hwang et al., 2009, J Korean Med Sci Dehdashti et al., 2008, Neurosurgery Netea-Maier et al., 2006, Eur J Endocrine Frank et al., 2006, Neuroendocrinology

$\begin{array}{cc}\begin{array}{c}\text { Initial overall remission } \\ \text { rate (\%) }\end{array} & \begin{array}{c}\text { Microadenoma } \\ \text { remission rate (\%) }\end{array} \\ 95 & 97 \\ 70 & \text { NA } \\ 80 & 73 \\ 81 & 100 \\ 77 & 79 \\ 68 & 68\end{array}$

